\title{
Pigment epithelium-derived factor (PEDF) negates hyperandrogenic PCOS features
}

\author{
Irit Miller'1, Hadas Bar-Joseph², Luba Nemerovsky', Ido Ben-Ami3,* and Ruth Shalgi1,* \\ 1Department of Cell and Developmental Biology, Sackler Faculty of Medicine, Tel-Aviv University, Ramat-Aviv, Tel-Aviv, Israel \\ ${ }^{2}$ The TMCR Unit, Sackler Faculty of Medicine, Tel-Aviv University, Ramat-Aviv, Tel-Aviv, Israel \\ 3IVF and Infertility Unit, Department of Obstetrics and Gynecology, Shaare Zedek Medical Center, Jerusalem, The Hebrew University Medical School \\ of Jerusalem, Jerusalem, Israel
}

Correspondence should be addressed to I Ben-Ami: idorit@netvision.net.il

*(I Ben-Ami and R Shalgi contributed equally to this work)

\begin{abstract}
Polycystic ovary syndrome (PCOS), one of the most common female endocrine disorder, is a prevalent cause of infertility. Hyperandrogenism is a key feature in PCOS and is correlated with increased expression of VEGF and cytokines in the ovaries. We have previously shown that pigment epithelium-derived factor (PEDF), an endogenous protein, presents potent anti-angiogenic and anti-inflammatory activities in the ovary and negates the effects of cytokines and VEGF. Additionally, PEDF plays a role in both pathophysiology and treatment of ovarian-hyperstimulation syndrome (OHSS), frequently seen in PCOS patients. We established hyperandrogenic-PCOS models, both in vivo, using mice exposed prenatally to dihydrotestosterone (DHT) and, in vitro, using human primary granulosa cells (hpGCS) and human granulosa cell line (KGN). In PCOSinduced mice, the mRNA levels of II-6, Vegf and Amh were higher than those of control; yet, treatment with rPEDF decreased these levels. Moreover, treating OHSS-induced PCOS-mice with rPEDF alleviated all OHSS symptoms. Stimulation of hpGCs with DHT resulted in downregulation of PEDF mRNA expression, concomitantly with a significant increase in $I L-6$ and $I L-8$ mRNAs expression. However, co-stimulation of DHT with rPEDF attenuated the increase in cytokines expression. The anti-inflammatory effect of PEDF was found to be mediated via PPAR $\gamma$ pathway. Our findings suggest that rPEDF treatment may normalize the ovarian angiogenic-inflammatory imbalance, induced by PCOSassociated hyperandrogenism. Moreover, the therapeutic potency of PEDF in preventing OHSS symptomes offers a rationale for using PEDF as novel physiological treatment for PCOS sequels.
\end{abstract}
Key Words
- PEDF
- PCOS
- inflammation
- OHSS

\section{Introduction}

Polycystic ovary syndrome (PCOS) is one of the most common female endocrine disorders, affecting $8-13 \%$ of women of reproductive age, and is a prevalent cause of female infertility (Azziz et al. 2016, Teede et al. 2018). It is a complex disorder associated with

reproductive, endocrine, metabolic and psychological features (Azziz et al. 2016, Teede et al. 2018). One of the major components of PCOS is hyperandrogenism. Accumulating evidence indicates that low-grade chronic inflammation and angiogenesis may also contribute to 
this syndrome (Goodarzi et al. 2011, Nandi et al. 2014, Azziz et al. 2016), although the relationship between the three factors is not well understood. PCOS women have elevated levels of luteinizing hormone (LH), which stimulates the production of androgens from the ovarian theca cells and causes hyperandrogenemia. This alters the hormonal milieu of sex steroids, leading to impaired folliculogenesis and ovulation (Dulka \& Moenter 2017). In addition, the increased activation of $5 \alpha$-reductase, frequently seen in PCOS patients, can convert testosterone to dihydrotestosterone (DHT), the most potent intracellular androgen (Münzker et al. 2015, Torchen et al. 2016, Marti et al. 2017). Furthermore, women with PCOS have an increased level of anti Müllerian hormone $(\mathrm{AMH})$, which is produced by granulosa cells (GCs). This high level appears to inhibit the FSH-induced aromatase activity, thus arresting follicular development (Goodarzi et al. 2011, Caldwell et al. 2014, Azziz et al. 2016). Additionally, patients with PCOS frequently present an enhanced expression of ovarian vascular endothelial growth factor (VEGF) and cytokines such as interleukin (IL) 6 and IL-8 (Artini et al. 2002, Tal et al. 2014, Adams et al. 2016, Fang et al. 2016). The previously mentioned pathological overproduction contributes to the increased incidence of ovarian hyperstimulation syndrome (OHSS) in PCOS patients, receiving hormonal stimulation under fertility treatments (Humaidan et al. 2010, Jayasena \& Franks 2014, Azziz et al. 2016). Their increased sensitivity to gonadotropins is nowadays treated by several approaches including low dose of gonadotropins and by replacing hCG with GnRH (Miller et al. 2016, Azziz et al. 2016).

For the past few years we have been studying the role of pigment epithelium-derived factor (PEDF) in the female reproductive system (Chuderland et al. 2014a). PEDF, a physiological potent anti-angiogenic and antiinflammatory factor, is known to counteract the activity of endothelial cells by inhibiting VEGF (Chuderland et al. 2013a). PEDF was also reported to serve as an antiinflammatory factor in kidney, retina and prostate cancer cells (Zhang et al. 2006, 2008, Wang et al. 2008, Hirsch et al. 2011, Liu et al. 2012), by inhibiting the production of IL-8 and IL-6 (Yamagishi et al. 2004, Yoshida et al. 2006). We have shown that the balance of PEDF/VEGF and of PEDF/ cytokines in the ovary is impaired in OHSS-induced mice (Chuderland et al. 2013b, Miller et al. 2016). Moreover, administration of recombinant PEDF (rPEDF) restored both the angiogenic and the inflammatory balance within the ovary, thus alleviating OHSS symptoms (Chuderland et al. 2013b, Miller et al. 2016).

(c) 2020 Society for Endocrinology Published by Bioscientifica Ltd. Printed in Great Britain
Until now, our research has focused on the role of PEDF in the pathogenesis and treatment of reproductiverelated maladies, such as OHSS and endometriosis (Chuderland et al. 2013b, 2014b, Miller et al. 2016). The shared features of these syndromes are faulty angiogenic and inflammatory processes, together with a reduced level of PEDF, implicating PEDF as a significant ovarian angiogenic-inflammatory regulator. Since PCOS is also associated with chronic inflammation and angiogenesis dysregulation, we were interested to characterize the effect of PEDF on the impaired ovarian homeostasis related to this syndrome.

\section{Materials and methods}

\section{Reagents}

Pregnant mare serum gonadotropin (PMSG; Syncropart, Sanofi), human chorionic gonadotropin (hCG; Sigma-Aldrich), lysophosphatidic acid (LPA; SigmaAldrich), Dulbecco's modified Eagle's medium/Ham F12 1:1 (DMEM-F12); Dulbecco's PBS (dPBS), L-glutamine, penicillin and streptomycin (Biological Industries, BeitHa'emek, Israel), fetal bovine serum (FBS; Invitrogen), GW9662 (GW; Sigma-Aldrich) and DMSO (SigmaAldrich).

\section{Ethical approval of animal use}

Animal care and all experiments were in accordance with the guidelines of the Institutional Animal Care and Use Committee, Sackler Faculty of Medicine, Tel-Aviv University, and were approved by the ethics committee (permit number \#M-15-093).

\section{Animals}

ICR female mice (Envigo RMS Limited, Jerusalem, Israel) were housed in temperature- and humidity-controlled rooms at the animal facility of the Sackler Faculty of Medicine, Tel Aviv University, under artificial illumination for $12 \mathrm{~h}$ daily. Food and water were provided ad libitum.

\section{Induction of PCOS in mice}

We followed the animal model of prenatal PCOS induction, described by Roland et al. (2010). Briefly, 8 -week-old female mice were mated according to their natural estrous cycle. The day of vaginal plug was 
considered as day 1 of gestation. Pregnant mice were injected subcutaneously (SC) on days 16-18 of gestation with $250 \mu \mathrm{g}$ of DHT (Sigma-Aldrich) dissolved in $100 \mu \mathrm{L}$ propanediol (Sigma-Aldrich) or with the same volume of vehicle (control mice). Female offspring were weaned on day 21 postpartum. Mice were divided arbitrarily into three groups: (1) Control mice: female offspring of control mothers; (2) PCOS mice: female offspring of DHT treated mothers; and (3) PCOS + rPEDF mice: female offspring of DHT treated mothers, where the offspring were treated with $\mathrm{PPEDF}$ every third day starting on day 21 postpartum. The progeny of control and PCOS mice were injected with vehicle at the same time points. At 8 weeks of age, mice were primed with PMSG (5 IU) and then killed for extraction of ovarian granulosa cell mRNA $(n=8$ mice per experimental group).

\section{OHSS-induced mouse model}

OHSS-induced mice were treated as described previously (Chuderland et al. 2013b, Miller et al. 2016). Briefly, 5-week-old mice were injected with 20 IU PMSG for 3 consecutive days (days $1-3$ ), followed, $24 \mathrm{~h}$ later, by a single injection of hCG (7 IU; day 4; Fig. 4A ' $\mathrm{b}$ '). Control mice were treated according to the standard superovulation regimen (Fig. 4A ' $a$ '): mice were injected with 7 IU hCG $48 \mathrm{~h}$ after administration of 5 IU PMSG. Mice were treated with either Tris or rPEDF ( $2 \mathrm{mg} / \mathrm{kg}$; SC) on days 1 and 4 ( $n=7$ mice per experimental group; Fig. $4 \mathrm{~A}$ ' $c-\mathrm{f}$ '). All mice were killed at day 6 ( $48 \mathrm{~h}$ after hCG injection).

\section{Permeability Miles assay}

The Miles assay was performed as previously described (Miller et al. 2016). Briefly, Evans blue was injected intravenously and fluids leaking from the blood into the abdomen were collected 30 min later by peritoneal lavage. The dye concentration in the fluids was evaluated by measuring the $\mathrm{OD}_{620}$.

\section{Human primary granulosa cells (hpGC)}

Women aged 22-38 years, undergoing planned in vitro fertilization (IVF) due to male factor infertility, were recruited to this study. All participants provided written informed consent forms prior to inclusion (IRB approval 18/14, Assaf Harofeh Medical Center, Israel). Women with PCOS and endometriosis were excluded from this study. Human primary granulosa cells were isolated from aspirated follicular fluids (FF) as described previously (Breckwoldt et al. 1996, Chuderland et al. 2013b) and cultured for 5 days in DMEM-F12 medium supplemented with 10\% FBS, $2 \mathrm{mM}$ L-glutamine, penicillin $(10,000 \mathrm{IU} / \mathrm{mL})$ and streptomycin $(10 \mathrm{mg} / \mathrm{mL})$. Cells were serum-starved $(0.1 \%$ FBS) for $8 \mathrm{~h}$ prior to stimulation. Women were treated with GnRH antagonist (Cetrorelix; Merck Serono or Orgalutran; Schering-Plough-Merck, NJ, USA) according to the antagonist protocol. Ovaries were stimulated with daily SC doses of recombinant follicle stimulating hormone (FSH; Gonal-F; Merck-Serono or Puregon Pen; ScheringPlough-Merck). Human menopausal gonadotropin (hMG; Menogon; Ferring) was administered from the third day of the menstrual cycle. When three leading follicles reached a diameter of $18 \mathrm{~mm}$, the patient received hCG (Ovitrelle; $250 \mathrm{mg}$; Merck Serono) to promote final oocyte maturation.

\section{Mice primary granulosa cells (mpGC)}

Cells were isolated according to Orly et al. (1980), with some modifications. Ovaries of 8-week-old mice were excised and transferred to Petri dishes containing serumfree DMEM-F12. Follicles were punctured with a $21 \mathrm{G}$ needle and the granulosa cells and cumulus-oocyte complexes were gently squeezed out of the follicles into the culture medium. The granulosa cells were centrifuged $(300 \boldsymbol{g}$ for 5 min), seeded in $10 \%$ serum-coated 24 -well plates (Nunc, Denmark) and cultured for $4 \mathrm{~h}$ in a humidified incubator at $37^{\circ} \mathrm{C}$ and $5 \% \mathrm{CO}_{2}$ in air.

\section{KGN cells}

The immortalized human granulosa cell line KGN (Nishi et al. 2001) was purchased from RIKEN BioResource Center (Iberaki, Japan). Granulosa cells were cultured in DMEM-F12 medium supplemented with 10\% FBS, $2 \mathrm{mM}$ L-glutamine, penicillin $(10,000 \mathrm{IU} / \mathrm{mL})$ and streptomycin (10 mg/mL). KGN cells were serum-starved in DMEM-F12 ( $0.1 \% \mathrm{FBS})$ for $16 \mathrm{~h}$ prior to stimulation. Cells were treated with DHT (10 nM) alone or with rPEDF (5 nM) for $24 \mathrm{~h}$. To inhibit peroxisome proliferator-activated receptor gamma, PPAR $\gamma$ cells were pre-treated with $10 \mu \mathrm{M}$ GW (a PPAR $\gamma$ antagonist) or DMSO $1 \mathrm{~h}$ before exposure to DHT and rPEDF for $24 \mathrm{~h}$. mRNA was determined in cell pellets after in vitro stimulation (all experiments were conducted at least three times). We used DHT instead of testosterone to avoid the chance of aromatization of testosterone to estradiol.

\section{PEDF production}

Human rPEDF (NM_002615.4) was expressed in E. coli BL21. Bacteria were allowed to grow at $30^{\circ} \mathrm{C}$ to an $\mathrm{OD}_{600 \mathrm{~nm}}$ 
of $0.5-0.6$, before induction for $4-5 \mathrm{~h}$ with $0.5 \mathrm{mmol} / \mathrm{L}$ isopropyl-1-thio- $\beta$-d-galactopyranoside centrifuged, and the pellet was lysed. Recombinant proteins were purified by ion metal affinity chromatography with Ni-NTA HisBind resin (Merck KGaA, Darmstadt, Germany) according to the manufacturer's protocol. Eluates with $>90 \%$ purity were dialyzed against Tris buffer, $\mathrm{pH} 10$ (Konson et al. 2010). Eluted fractions were resolved by sodium dodecyl sulfate PAGE (SDS-PAGE; Bio-Rad, Israel), and proteins were stained with GelCode (Blue Stain Reagent, Thermo scientific) or Western blotted with a specific anti-PEDF antibody (sc-25594, Santa-Cruz Biotechnology).

\section{RNA extraction}

Total RNA was extracted from granulosa cells or mice ovaries using Trizol reagent (Bio-Tri; Bio-lab, Jerusalem, Israel) according to the manufacturer's instructions and quantified with the Nano-Drop spectrophotometer (ND1000; Thermo Scientific). First-strand cDNA was prepared by the high-capacity cDNA RT kit (Applied Biosystems; 10 ng RNA fractions). Changes in the level of expression of mRNA were detected by real-time PCR (qPCR), performed using SYBR green reagent (Power SYBR Green PCR Master Mix; Applied Biosystems) together with 15 ng cDNA and specific primers, on a StepOnePlus Real-Time PCR System (Applied Biosystems). Gene expression was detected using specific primersfor IL-6, IL-8, PEDF, VEGF, RPLPO, RPLP2 and PPAR $\gamma$ (assay identification (ID): IL-6, Mm00446190_m1; IL-6, Rn01410330_m1; IL-6, Hs00985639_m1; IL-8, Hs00174103_m1; PEDF, Mm00441270_m1; PEDF, Hs01106937_m1; VEGF, Mm00437306_m1; VEGF, Hs00900055_m1; AMH, Mm004310795_g1; Rplp2, Mm00782638_s1; and RPLP0, Hs99999902_m1) by TaqMan® Universal PCR Master Mix (Life Technologies). Relative expression was calculated using the comparative $\Delta \mathrm{Ct}$.

\section{Statistics}

All statistical analyses were performed by SPSS (SPSS Inc). Relative protein, mRNA and immunoassay results are expressed as mean $(\mathrm{M}) \pm$ s.E.M. and compared as appropriate for data distribution. Data normality was assessed using Kolmogorov-Smirnov tests. In all instances where raw data were not normally distributed, square root or log transformation were applied to normalize data. Normally distributed data were then evaluated by one-way ANOVA followed by Tukey post hoc or parametric two-tailed Student's $t$-test with equal variance $t$-test to evaluate significance. Data are presented as percent normalized to control. $P$ value of $<0.05$ was considered as statistically significant.

\section{Results}

\section{Differential expression of angiogenic and inflammatory mediators in granulosa cells of PCOS mice}

We used the prenatal PCOS model described by Roland et al. (2010), in which pregnant mice are injected with DHT. Offspring of females that were not induced for PCOS (injected with vehicle) served as control. The timing of vaginal opening (a marker for puberty onset) in female offspring was recorded as a marker of puberty onset; it was delayed in PCOS mice (data not shown).

PCOS females were then divided arbitrarily into two groups: (1) PCOS and (2) PCOS+rPEDF. Examination of genes of interest in mpGCs from the different experimental groups revealed that the most striking change was observed in the level of Il-6 mRNA, which was a ten-fold higher in PCOS mice than in controls, non PCOS $(P<0.05$; Fig. 1A). The levels of VEGF and AMH mRNAs were also higher in the PCOS mice than in the controls $(P<0.05$; Fig. 1A). Treatment of the PCOS mice with rPEDF reversed the elevated levels of Il-6, Vegf and Amh to that found in control mice $(P<0.05$; Fig. $1 \mathrm{~A})$. Moreover, PCOS mice treated with rPEDF had higher levels of Ppary mRNA than untreated PCOS mice $(P<0.05$; Fig. $1 \mathrm{~A})$.

The level of PEDF mRNA was the same in control, PCOS and rPEDF-treated PCOS mice (Fig. 1A). However, the Pedf/Il-6 and Pedf/Vegf ratios were higher in rPEDFtreated PCOS mice than in PCOS mice by 6 and 12 folds, respectively $(P<0.05$; Fig. $1 \mathrm{~B}$ and $\mathrm{C})$.

\section{rPEDF inhibits the DHT-induced expression of IL- 6 and IL-8 mRNA in hpGCs}

Our aim was to examine the anti-inflammatory role of rPEDF in in vitro PCOS model. Given that hyperandrogenism is a hallmark of PCOS, we used primary human granulosa cells (hpGCs) treated with DHT (10 ng/mL; Adams et al. 2016) and found a significant increase in the levels of both $I L-6$ and $I L-8$ mRNA $(P<0.05$; Fig. 2B and $\mathrm{C}$, respectively; middle bar).

In contrast, the level of PEDF mRNA was downregulated $(P<0.001$; Fig. 2A), suggesting that DHT counter regulates the levels of mRNA for PEDF and cytokines. 
A

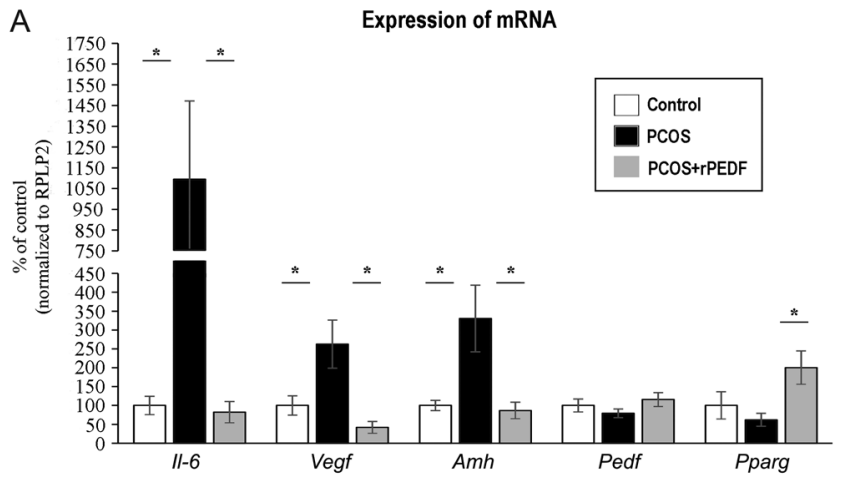

B

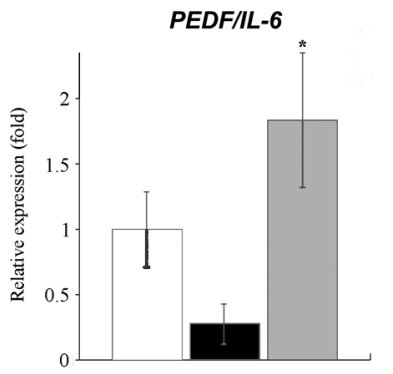

C

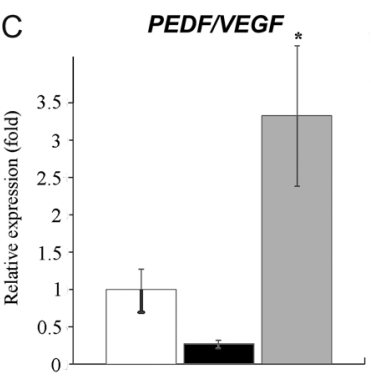

Figure 1

Expression of mRNA in mpGC. (A) Control, PCOS and PCOS + rPEDF mpGCs were isolated from the follicles of 8-week-old mice primed with PMSG (5 IU). mRNA was extracted from the cells, analyzed with qPCR primers specific for PEDF, PPARy, AMH, IL-6 and VEGF and calibrated with RPLP2 (relative expression; $n=8$ mice per experimental group). The figure presents the ratio of mRNA expression of PEDF/IL-6 (B) or PEDF/VEGF (C). Bars are mean \pm S.E.M., normalized to control mice (presented as $100 \%$; ANOVA). ${ }^{*} P<0.05$ - significantly different from PCOS value.

Because hyperandrogenism elevates the levels of cytokines, we tested whether exogenous PEDF could negate this increase. Co-stimulation of hpGC with DHT and rPEDF (5 nM) diminished the DHT-induced elevation of $I L-6$ and $I L-8$ mRNAs $(P<0.05$; Fig. $2 \mathrm{~B}$ and $\mathrm{C}$, respectively; right bars). These data provide further evidence for an anti-inflammatory effect of PEDF in GCs.

\section{The anti-inflammatory effect of rPEDF is mediated via the PPAR $\gamma$ pathway}

The anti-inflammatory function of PEDF in prostate cancer cells was shown to be mediated by the up-regulation of $\operatorname{PPAR} \gamma$, raising the question of whether the same mechanism is utilized in GCs. To test that, we used KGN cells that express PEDF receptors (LR, ATGL and LRP6; data not shown) and we used an in vitro hyperandrogenic PCOS model (Dilaver et al. 2019) to study the mechanism of androgens associated PCOS. Similar to the results obtained in hpGCs, DHT stimulation significantly increased the expression of both $I L-6$ and $I L-8$ mRNAs in the KGN cells, whereas co-stimulation with rPEDF
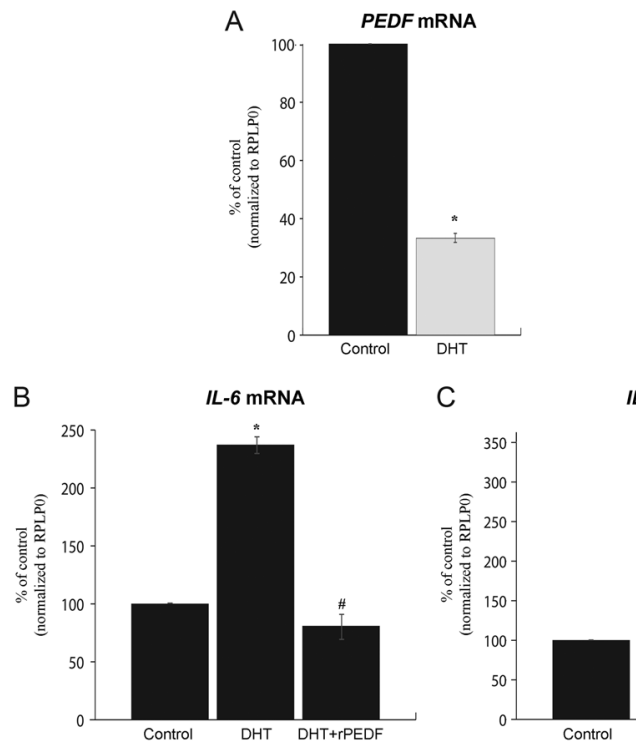

IL-8 mRNA

\section{Figure 2}

DHT downregulates PEDF expression concurrently with upregulation of IL-6 and IL-8 expression in hpGCs. Serum-starved hpGCs were treated for $24 \mathrm{~h}$ with DHT $(10 \mathrm{ng} / \mathrm{mL}$ ) or co-stimulated with both DHT and rPEDF (5 $\mathrm{nM}$ ). Non-treated cells served as control. The corresponding mRNAs were subjected to qPCR analysis (relative expression), with specific primers for PEDF, IL- 6 or IL- 8 and calibrated by the endogenous RPLPO. All experiments were conducted at least three times. Bars are mean \pm S.E.M. of relative expression. ${ }^{*} P<0.05$ - significantly different from control value, $\# P<0.05$ - significantly different from $D H T$ value (ANOVA).

inhibited this DHT-induced elevation of cytokines (Fig. 3A and B). Interestingly, pre-treatment with GW9662, which is a selective $P P A R \gamma$ antagonist, prior to co-stimulation with DHT and rPEDF reversed the effect of PEDF and maintained the DHT-induced upregulation of IL- 6 and IL-8 in (Fig. 3A and B, right bars).

To examine whether PPAR $\gamma$ mediates the antiinflammatory effect of PEDF in other inflammatory stimulations, we used our previous findings which demonstrated that PEDF represses the increase of LPAinduced IL-6 and IL-8 expression (Miller et al. 2016). Here, we treated KGN cells with LPA and rPEDF, either alone or in combination with GW. We observed that GW negated the anti-inflammatory effect exerted by PEDF on the LPAinduced increased expression of cytokine mRNA (Fig. 3C and D), supporting that the anti-inflammatory function of PEDF in GCs is mediated via its downstream effector PPAR .

\section{rPEDF treatment prevents OHSS symptoms in PCOS mice}

Because PCOS is a major risk factor of developing OHSS, we evaluated whether our PCOS-mice model may serve as 
A

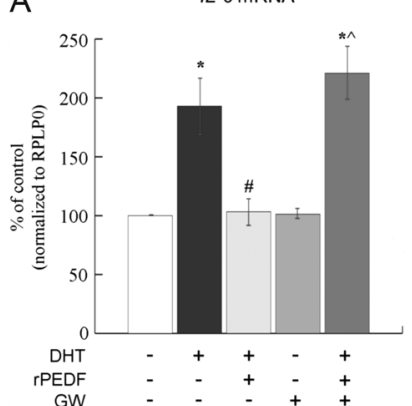

B

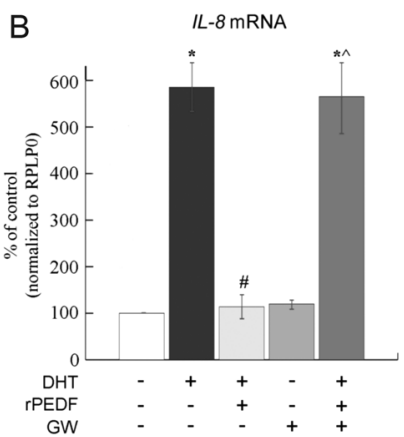

C

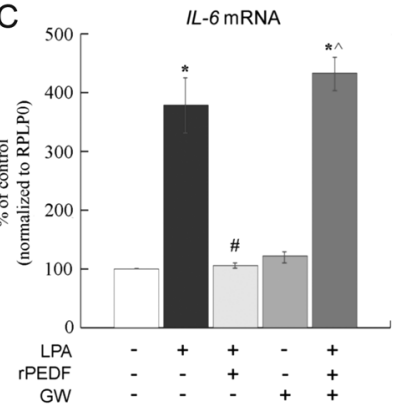

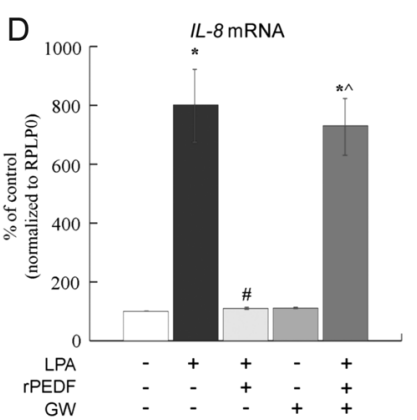

Figure 3

The anti-inflammatory effect of rPEDF is mediated via the PPAR $\gamma$ pathway in KGN cells. Serum-starved KGN cells were treated with DHT $(10 \mathrm{ng} / \mathrm{mL})$ alone, DHT and rPEDF $(5 \mathrm{nM})$, GW $(1 \mu \mathrm{M})$ alone or a combination of all three (A and B) or treated with LPA $(10 \mu \mathrm{M})$ alone, rPEDF $(5 \mathrm{nM})$ alone, a combination of both, GW $(1 \mu \mathrm{M})$ alone or a combination of all three (C and D). Non-treated cells served as control. The corresponding mRNAs were subjected to $\mathrm{QPCR}$ analysis (relative expression), with specific primers for IL-6 (A and C) or for IL-8 (B and D), and calibrated by the endogenous RPLPO. All experiments were conducted at least three times. Bars are mean \pm S.E.M. of relative expression. ${ }^{*} P<0.05$ - significantly different from control value; $\# P<0.05$ - significantly different from DHT or LPA value; ${ }^{\wedge} P<0.05$ - significantly different from rPEDF value (ANOVA). a competent research model at the clinic. We examined six experimental mice groups (see Materials and methods; Fig. 4A): control superovulation (a); OHSS (b); PCOS and OHSS (c); PCOS and OHSS treated with rPEDF (d); PCOS administered a standard superovulation protocol (e) and PCOS administered a standard superovulation protocol along with rPEDF (f). Consistent with our previous findings (Chuderland et al. 2013b, Miller et al. 2016), OHSS-induced mice (b) presented all the characteristic OHSS symptoms - hyperpermeability $(P<0.05$; Fig. $4 \mathrm{~B})$, increased ovarian weight $(P<0.05$; Fig. $4 \mathrm{C})$ and edema, as evidenced by a significant gain of body weight $(P<0.05$; Fig. 4D), compared to control mice (a). The same profile was observed in OHSS-induced PCOS mice $((\mathrm{c}) ; P<0.05)$. Interestingly, PCOS-mice treated with a standard superovulation protocol (e) exhibited the same OHSS symptoms as OHSS-induced mice (b; Fig. 4B, C and D), which resembles the situation seen in the clinic.

We have previously used a mouse model to show that treatment with rPEDF can alleviate OHSS symptoms (Chuderland et al. 2013b, Miller et al. 2016). When we examined the effect of administration of rPEDF on PCOS mice and found that rPEDF treatment prevented the fluid leakage (Fig. 4D) seen in OHSS-induced PCOS mice (d), compared to vehicle (c). This was accompanied by alleviation of other OHSS symptoms monitored, namely ovarian weight and the gain of body weight (Fig. 4C and D). Moreover, rPEDF also reduced OHSS symptoms in standard super-ovulated PCOS-mice (f) compared to vehicle (e; Fig. 4B, C and D), suggesting that rPEDF may
A

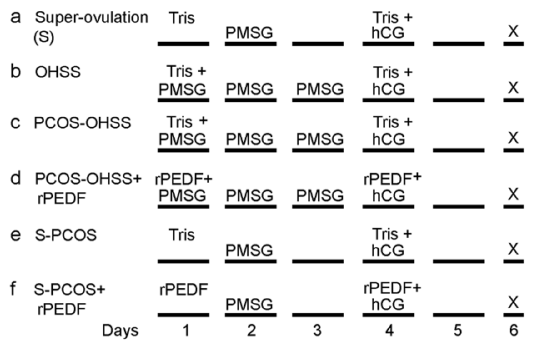

C

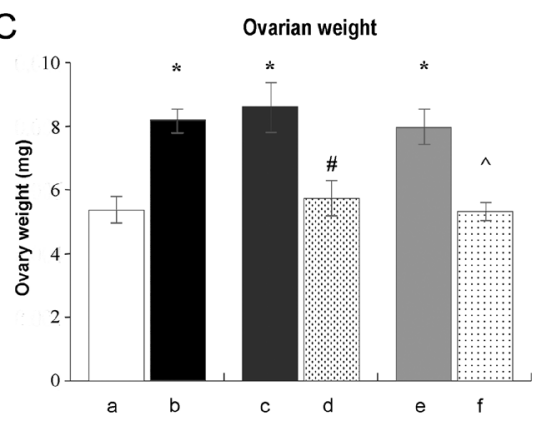

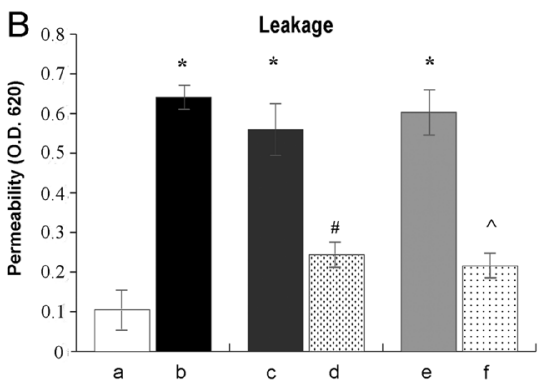

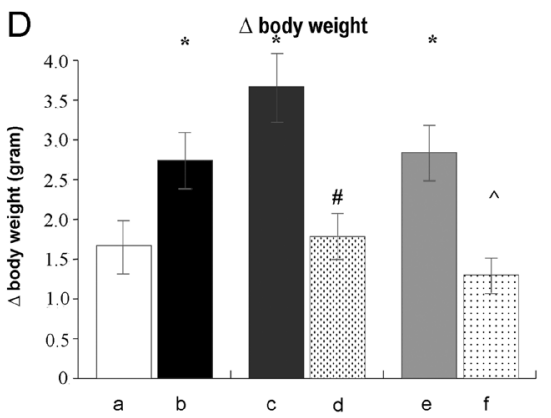

\section{Figure 4}

rPEDF treatment inhibits OHSS symptoms in PCOS mice. Schematic representation of the experimental design (a-f). All mice were killed $(X)$ on day 6 (A). Leakage of fluids into the peritoneum was assessed by Miles assay (B). Ovarian weight ( $\mathrm{mg}$; $\mathrm{C}$ ) was determined after mice were killed. Edema assessed by monitoring changes in body weight (grams) throughout the treatment (D) ( $n=7$ mice per experimental group). Bars are mean \pm S.E.M., $* P<0.05$ significantly different from superovulation (S) mice $(A)$ value, $\# P<0.05$ significantly different from PCOS-OHSS mice $(C)$ value and $\wedge P<0.05$ from S-PCOS mice $(E)$ value (ANOVA). 
be effective in OHSS ( $d$ and $\mathrm{f}$ ) regardless of the underlying risk factor of its occurrence (c and e)

\section{Discussion}

PCOS is a complex syndrome, associated with elevated levels of androgens, cytokines and angiogenic factors (Goodarzi et al. 2011, Caldwell et al. 2014, Azziz et al. 2016). Hyperandrogenism is a key feature of the syndrome (Filippou \& Homburg 2017) and prenatal exposure to androgens can induce a variety of PCOS-like characteristic symptoms in animal models. These mice present irregular cycles and oligo-ovulation or an-ovulation, decreased progesterone and follicular atresia, all components of human PCOS (Roland et al. 2010, Caldwell et al. 2017). We have already used this model and validated it in our previous studies (Chuderland et al. 2014a, Silber et al. 2019). The specific mechanism by which androgens elicit these symptoms is not yet clear; however, chronic ovarian inflammation could also play a role in PCOS-related ovarian dysfunction (Xita \& Tsatsoulis 2006, Deligeoroglou et al. 2012). Accumulating data demonstrate increased levels of several pro-inflammatory cytokines, including IL-6 and tumor necrosis factor- $\alpha$, in the FF of PCOS patients (González et al. 2014, Adams et al. 2016).

In the current study, our aim was to characterize the mechanism behind the fertility impairment of PCOS patients, using an hyperandrogenic PCOS-mice model, in which the mice do not display insulin resistance (Caldwell et al. 2014). Our findings suggest that hyperactivation of the inflammatory and angiogenic pathways were negated by PEDF. The in vivo results indicate different mpGC expression of inflammatory-angiogenic related genes in PCOS-mice than that of control mice, demonstrating increased expression of IL-6 and Vegf and similar to data acquired from PCOS patients (Adams et al. 2016). These patients also have high levels of AMH in their serum, FF and GCs (Bhide et al. 2015, Karakas 2017, Sathyapalan et al. 2018, Liu et al. 2019); similarly, the current study demonstrates upregulation of AMH in GCs of hyperandrogenic PCOS-mice.

PCOS patients exhibit high levels of serum PEDF (Yang et al. 2011) as reported in a recent study by our group performed in a metabolic PCOS mice model (met. PCOS), which was induced by feeding with high-fat diet (Silber et al. 2019). In the current hyperandrogenic PCOSmice model, the level of PEDF mRNA did not change. This discrepancy could be explained by the use of two different models, as met.PCOS mice are IR, obese and retain a large mass of fat, which is the major source of body PEDF. Interestingly, treating hyperandrogenic PCOS-mice with rPEDF abolished the reported upregulation of IL-6, VEGF and AMH mRNA levels, compared to non-treated hyperandrogenic PCOS-mice.

Furthermore, our in vivo findings demonstrated increased expression of Ppary, an anti-inflammatory mediator, in GC extracted from hyperandrogenic PCOSmice treated with rPEDF. In a previous study, we have shown that PEDF modulates both the inflammatory and angiogenic pathways and that these pathways act in parallel and are independent (Miller et al. 2016). To reveal the anti-inflammatory mechanism of PEDF in attenuating the effect of DHT-induced PCOS, we used an in vitro model of DHT-stimulated hpGCs and KGN cells, where $I L-6$ and IL-8 mRNAs were upregulated, similar to the effect of LPA. Co-stimulation of rPEDF with either DHT or LPA resulted in a significant attenuation of the stimulated inflammatory response. Previous publications have shown that PPAR $\gamma$ is downstream to the PEDF anti-inflammatory pathway and that PEDF increases both expression and activation of PPAR $\gamma$ in podocytes and prostate cancer cells (Hirsch et al. 2011, Ishibashi et al. 2012); yet, this pathway is far from being characterized. In our study, we aimed to validate this pathway in inflammatory-induced granulosa cells (with either DHT or LPA) by challenging PPAR $\gamma$ activity, using a specific PPAR $\gamma$ inhibitor. Our findings suggest a similar mechanism to that observed in prostate cells (Hirsch et al. 2011), as PPAR $\gamma$ inhibition abolished the effect of rPEDF under DHT or LPA stimulation. Our finding that PEDF increases PPAR level, thereby inhibiting the increase of the pro-inflammatory cytokines level, may suggest a possible therapeutic mechanism activated by the clinically-used PPAR $\gamma$ agonists such as thiazolidinedione (Yki-Järvinen 2004, Chen et al. 2009) and metformin (Ljubicic \& Jasmin 2015). These findings demonstrate a beneficial effect of PEDF on the excessive expression of cytokines and VEGF in the ovary, implying a therapeutic potential of PEDF in overcoming the impaired inflammatory-angiogenichormonal ovarian balance known to play a role in PCOS pathophysiology, thus restoring the physiological ovarian balance.

Our results demonstrated that PCOS-mice are prone to develop OHSS symptoms, even when subjected to a standard superovulation protocol, mimicking the clinical conditions. Both OHSS and PCOS involve excessive activation of the inflammatory and angiogenic pathways. We have also shown that PEDF could prevent OHSS symptoms in a mouse model by attenuating the secretion of ovarian cytokines and VEGF, which are the 
A

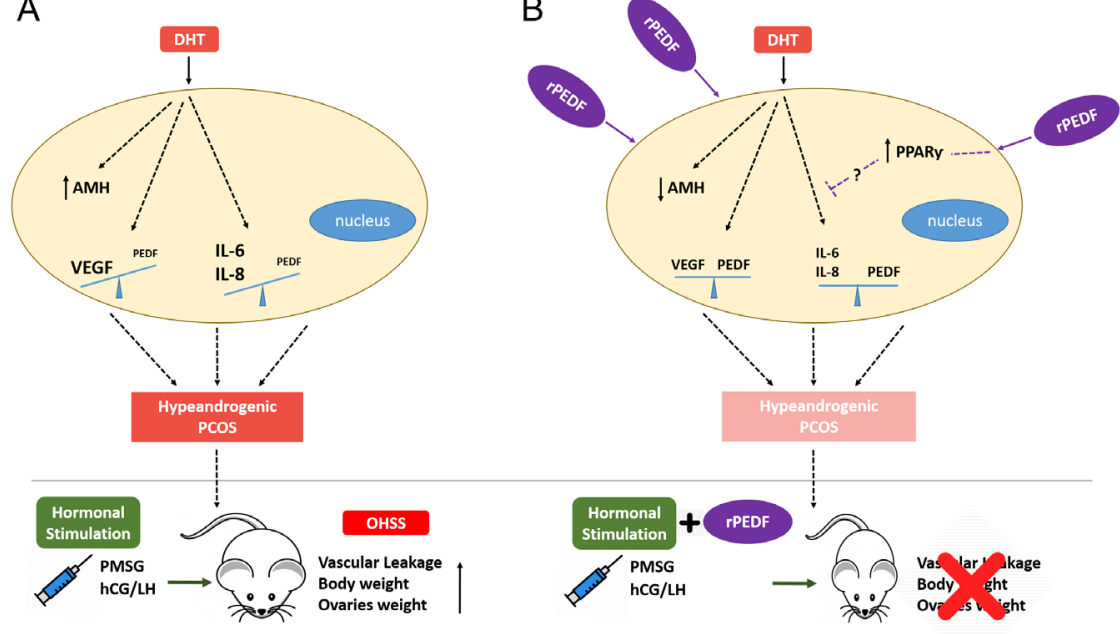

\section{Figure 5}

The role of PEDF in treatment of hyperandrogenic PCOS-mice model (scheme). Under

hyperandrogenic conditions, granulosa cells present excessive levels of inflammation and vascularization, manifested by elevated levels of VEGF, IL-6, IL-8 and AMH (A; upper panel). As a result, hyperandrogenic PCOS-mice are prone to develop OHSS, even under standard hormonal stimulation ( $A$; lower panel). The impaired ovarian balance can be restored by treatment with PEDF, via PPAR $(\mathrm{B}$; upper panel), preventing OHSS development ( $\mathrm{B}$; lower panel). A full-colour version of this figure is available at https://doi. org/10.1530/JOE-19-0603. major contributors to the pathophysiology of OHSS (Chuderland et al. 2013b, Miller et al. 2016). In the current study, we investigated the therapeutic efficacy of rPEDF in relieving OHSS symptoms in the hyperandrogenic PCOS-mice model. PEDF administration prevented vascular hyperpermeability and alleviated all related OHSS symptoms, including weight gain and ovarian enlargement, both in OHSS-induced PCOS-mice and in PCOS-mice triggered for standard superovulation. Because women with PCOS who undergo ovarian stimulation face an increased risk of developing OHSS, these findings indicate another potential therapeutic feature of PEDF.

In summary (Fig. 5), the data gathered from our studies implicate PEDF as a central regulatory physiological factor in the ovary. Our findings gathered from hyperandrogenic PCOS-mice model illustrate the complexity of the pathophysiology. It is correlated with excessive levels of androgens, inflammation and vascularization and manifested by elevated levels of VEGF, IL-6, IL-8 and AMH (Fig. 5A, upper panel). Hyperandrogenic PCOS-mice are prone to develop OHSS even under standard hormonal stimulation manifested by increased ovarian and body weight and vascular leakage (Fig. 5A, lower panel). The impaired ovarian inflammatory-angiogenic balance can be restored by treatment with PEDF via its downstream effector PPAR (Fig. 5B, upper panel), thus preventing OHSS development (Fig. 5B, lower panel).

Elucidating the precise anti-angiogenic and antiinflammatory mechanism of PEDF in the ovary could pave the way to develop novel biological therapeutic agents to treat OHSS in women, regardless of their PCOS status.
Declaration of interest

I B-A, H B-J and R S are inventors of U.S. Patent 8962561 and EU patent 2598806. The other authors have nothing to declare.

\section{Funding}

This work was partially supported by a grant from the Israel Science Foundation (No. 1934/13 to I B A) and grant from the Dr Leo Mintz Research Fund in Obstetrics and Gynecology, Sackler Faculty of Medicine, Tel Aviv University, Tel Aviv Israel.

\section{Author contribution statement}

This work was performed in partial fulfillment of the requirements for a PhD degree of Irit Miller, at the Sackler Faculty of Medicine, Tel Aviv University, Israel. Irit Miller designed the study and carried out the experimental work, analyzed the data and drafted the manuscript. Hadas Bar-Joseph and Luba Nemerovsky assisted in the in vivo experiments and Ido Ben-Ami participated in analyzing and discussing the results and helped drafting the manuscript. Ruth Shalgi conceived the study, participated in its design and coordination, helped draft the manuscript and supervised the study. Ido Ben-Ami and Ruth Shagi contributed equally to this work.

\section{Acknowledgements}

The authors are grateful to Dr Dana Chuderland for her valuable consultancy and help with discussing the findings of this study and to Ruth Kaplan-Kraicer (Sackler Faculty of Medicine, Tel Aviv University) for her excellent assistance in preparing the manuscript. The authors thank Prof T Yanase and Prof Y Nishi (Department of Endocrinology and Diabetes Mellitus, School of Medicine, Fukuoka University, Fukuoka, Japan) for providing the KGN cells.

\section{References}

Adams J, Liu Z, Ren YA, Wun WS, Zhou W, Kenigsberg S, Librach C, Valdes C, Gibbons W \& Richards J 2016 Enhanced inflammatory 
transcriptome in the granulosa cells of women with polycystic ovarian syndrome. Journal of Clinical Endocrinology and Metabolism 101 3459-3468. (https://doi.org/10.1210/jc.2015-4275)

Artini PG, Monti M, Fasciani A, Battaglia C, D’Ambrogio G \& Genazzani AR 2002 Vascular endothelial growth factor, interleukin-6 and interleukin-2 in serum and follicular fluid of patients with ovarian hyperstimulation syndrome. European Journal of Obstetrics, Gynecology, and Reproductive Biology 101 169-174. (https://doi. org/10.1016/s0301-2115(01)00568-1)

Azziz R, Carmina E, Chen Z, Dunaif A, Laven JSE, Legro RS, Lizneva D, Natterson-Horowtiz B, Teede HJ \& Yildiz BO 2016 Polycystic ovary syndrome. Nature Reviews: Disease Primers 2 16057. (https://doi. org/10.1038/nrdp.2016.57)

Bhide P, Dilgil M, Gudi A, Shah A, Akwaa C \& Homburg R 2015 Each small antral follicle in ovaries of women with polycystic ovary syndrome produces more antiMüllerian hormone than its counterpart in a normal ovary: an observational cross-sectional study. Fertility and Sterility 103 537-541. (https://doi.org/10.1016/j. fertnstert.2014.10.033)

Breckwoldt M, Selvaraj N, Aharoni D, Barash A, Segal I, Insler V \& Amsterdam A 1996 Expression of Ad4-BP/cytochrome P450 side chain cleavage enzyme and induction of cell death in long-term cultures of human granulosa cells. Molecular Human Reproduction 2 391-400. (https://doi.org/10.1093/molehr/2.6.391)

Caldwell ASL, Middleton LJ, Jimenez M, Desai R, McMahon AC, Allan CM, Handelsman DJ \& Walters KA 2014 Characterization of reproductive, metabolic, and endocrine features of polycystic ovary syndrome in female hyperandrogenic mouse models. Endocrinology 155 3146-3159. (https://doi.org/10.1210/en.2014-1196)

Caldwell ASL, Edwards MC, Desai R, Jimenez M, Gilchrist RB, Handelsman DJ \& Walters KA 2017 Neuroendocrine androgen action is a key extraovarian mediator in the development of polycystic ovary syndrome. PNAS 114 E3334-E3343. (https://doi.org/10.1073/ pnas.1616467114)

Chen Q, Sun X, Chen J, Cheng L, Wang J, Wang Y \& Sun Z 2009 Direct rosiglitazone action on steroidogenesis and proinflammatory factor production in human granulosa-lutein cells. Reproductive Biology and Endocrinology 7 147. (https://doi.org/10.1186/1477-7827-7-147)

Chuderland D, Ben-Ami I, Kaplan-Kraicer R, Grossman H, Komsky A, Satchi-Fainaro R, Eldar-Boock A, Ron-El R \& Shalgi R 2013a Hormonal regulation of pigment epithelium-derived factor (PEDF) in granulosa cells. Molecular Human Reproduction 19 72-81. (https://doi. org/10.1093/molehr/gas046)

Chuderland D, Ben-Ami I, Kaplan-Kraicer R, Grossman H, Ron-El R \& Shalgi R 2013b The role of pigment epithelium-derived factor in the pathophysiology and treatment of ovarian hyperstimulation syndrome in mice. Journal of Clinical Endocrinology and Metabolism 98 E258-E266. (https://doi.org/10.1210/jc.2012-3037)

Chuderland D, Ben-Ami I, Bar-Joseph H \& Shalgi R 2014a Role of pigment epithelium-derived factor in the reproductive system. Reproduction 148 R53-R61. (https://doi.org/10.1530/REP-14-0251)

Chuderland D, Ben-Ami I, Friedler S, Hasky N, Ninio-Many L, Goldberg K, Bar-Joseph H, Grossman H \& Shalgi R 2014b Hormonal regulation of pigment epithelium-derived factor (PEDF) expression in the endometrium. Molecular and Cellular Endocrinology 390 85-92. (https://doi.org/10.1016/j.mce.2014.04.006)

Deligeoroglou E, Vrachnis N, Athanasopoulos N, Iliodromiti Z, Sifakis S, Iliodromiti S, Siristatidis C \& Creatsas G 2012 Mediators of chronic inflammation in polycystic ovarian syndrome. Gynecological Endocrinology 28 974-978. (https://doi.org/10.3109/09513590.2012. 683082)

Dilaver N, Pellatt L, Jameson E, Ogunjimi M, Bano G, Homburg R, D Mason H \& Rice S 2019 The regulation and signalling of antiMüllerian hormone in human granulosa cells: relevance to polycystic ovary syndrome. Human Reproduction 34 2467-2479. (https://doi. org/10.1093/humrep/dez214)
Dulka EA \& Moenter SM 2017 Prepubertal development of gonadotropinreleasing hormone neuron activity is altered by sex, age, and prenatal androgen exposure. Endocrinology 158 3943-3953. (https://doi. org/10.1210/en.2017-00768)

Fang Y, Lu X, Liu L, Lin X, Sun M, Fu J, Xu S \& Tan Y 2016 Vascular endothelial growth factor induces antiMüllerian hormone receptor 2 overexpression in ovarian granulosa cells of in vitro fertilization/ intracytoplasmic sperm injection patients. Molecular Medicine Reports 13 5157-5162. (https://doi.org/10.3892/mmr.2016.5173)

Filippou P \& Homburg R 2017 Is foetal hyperexposure to androgens a cause of PCOS? Human Reproduction Update 23 421-432. (https://doi. org/10.1093/humupd/dmx013)

González F, Sia CL, Bearson DM \& Blair HE 2014 Hyperandrogenism induces a proinflammatory TNF $\alpha$ response to glucose ingestion in a receptor-dependent fashion. Journal of Clinical Endocrinology and Metabolism 99 E848-E854. (https://doi.org/10.1210/jc.2013-4109)

Goodarzi MO, Dumesic DA, Chazenbalk G \& Azziz R 2011 Polycystic ovary syndrome: etiology, pathogenesis and diagnosis. Nature Reviews: Endocrinology 7 219-231. (https://doi.org/10.1038/nrendo.2010.217)

Hirsch J, Johnson CL, Nelius T, Kennedy R, de Riese W \& Filleur S 2011 PEDF inhibits IL8 production in prostate cancer cells through PEDF receptor/phospholipase $\mathrm{A} 2$ and regulation of NFkB and PPAR $\gamma$. Cytokine 55 202-210. (https://doi.org/10.1016/j.cyto.2011.04.010)

Humaidan P, Quartarolo J \& Papanikolaou EG 2010 Preventing ovarian hyperstimulation syndrome: guidance for the clinician. Fertility and Sterility 94 389-400. (https://doi.org/10.1016/j.fertnstert.2010.03.028)

Ishibashi Y, Matsui T, Ohta K, Tanoue R, \& Takeuchi M 2012 PEDF inhibits AGE-induced podocyte apoptosis via PPAR-gamma activation. Microvascular Research 85 54-58. (https://doi.org/10.1016/j. mvr.2012.10.007)

Jayasena CN \& Franks S 2014 The management of patients with polycystic ovary syndrome. Nature Reviews: Endocrinology 10 624-636. (https://doi.org/10.1038/nrendo.2014.102)

Karakas SE 2017 New biomarkers for diagnosis and management of polycystic ovary syndrome. Clinica Chimica Acta: International Journal of Clinical Chemistry 471 248-253. (https://doi.org/10.1016/j. cca.2017.06.009)

Konson A, Pradeep S \& Seger R 2010 Phosphomimetic mutants of pigment epithelium-derived factor with enhanced antiangiogenic activity as potent anticancer agents. Cancer Research 70 6247-6257. (https://doi.org/10.1158/0008-5472.CAN-10-0434)

Liu Y, Leo LF, McGregor C, Grivitishvili A, Barnstable CJ \& TombranTink J 2012 Pigment epithelium-derived factor (PEDF) peptide eye drops reduce inflammation, cell death and vascular leakage in diabetic retinopathy in Ins2(Akita) mice. Molecular Medicine 18 1387-1401. (https://doi.org/10.2119/molmed.2012.00008)

Liu XY, Yang YJ, Tang CL, Wang K, Chen JJ, Teng XM, Ruan YC \& Yang JZ 2019 Elevation of antiMüllerian hormone in women with polycystic ovary syndrome undergoing assisted reproduction: effect of insulin. Fertility and Sterility 111 157-167. (https://doi.org/10.1016/j. fertnstert.2018.09.022)

Ljubicic V \& Jasmin BJ 2015 Metformin increases peroxisome proliferatoractivated receptor $\gamma$ co-activator- $1 \alpha$ and utrophin a expression in dystrophic skeletal muscle. Muscle and Nerve 52 139-142. (https://doi. org/10.1002/mus.24692)

Marti N, Galván JA, Pandey AV, Trippel M, Tapia C, Müller M, Perren A \& Flück CE 2017 Genes and proteins of the alternative steroid backdoor pathway for dihydrotestosterone synthesis are expressed in the human ovary and seem enhanced in the polycystic ovary syndrome. Molecular and Cellular Endocrinology 441 116-123. (https://doi. org/10.1016/j.mce.2016.07.029)

Miller I, Chuderland D, Grossman H, Ron-El R, Ben-Ami I \& Shalgi R 2016 The dual role of PEDF in the pathogenesis of OHSS: negating both angiogenic and inflammatory pathways. Journal of Clinical Endocrinology and Metabolism 101 4699-4709. (https://doi. org/10.1210/jc.2016-1744) https://joe.bioscientifica.com

https://doi.org/10.1530/JOE-19-0603 (c) 2020 Society for Endocrinology Published by Bioscientifica Ltd. Printed in Great Britain 
Münzker J, Hofer D, Trummer C, Ulbing M, Harger A, Pieber T, Owen L, Keevil B, Brabant G, Lerchbaum E, et al. 2015 Testosterone to dihydrotestosterone ratio as a new biomarker for an adverse metabolic phenotype in the polycystic ovary syndrome. Journal of Clinical Endocrinology and Metabolism 100 653-660. (https://doi. org/10.1210/jc.2014-2523)

Nandi A, Chen Z, Patel R \& Poretsky L 2014 Polycystic ovary syndrome. Endocrinology and Metabolism Clinics of North America 43 123-147. (https://doi.org/10.1016/j.ecl.2013.10.003)

Nishi Y, Yanase T, Mu Y, Oba K, Ichino I, Saito M, Nomura M, Mukasa C, Okabe T, Goto K, et al. 2001 Establishment and characterization of a steroidogenic human granulosa-like tumor cell line, KGN, that expresses functional follicle-stimulating hormone receptor. Endocrinology 142 437-445. (https://doi.org/10.1210/ endo.142.1.7862)

Orly J, Sato G \& Erickson GF 1980 Serum suppresses the expression of hormonally induced functions in cultured granulosa cells. Cell 20 817-827. (https://doi.org/10.1016/0092-8674(80)90328-1)

Roland AV, Nunemaker CS, Keller SR \& Moenter SM 2010 Prenatal androgen exposure programs metabolic dysfunction in female mice. Journal of Endocrinology 207 213-223. (https://doi.org/10.1677/JOE10-0217)

Sathyapalan T, Al-Qaissi A, Kilpatrick ES, Dargham SR \& Atkin SL 2018 Anti-Müllerian hormone measurement for the diagnosis of polycystic ovary syndrome. Clinical Endocrinology 88 258-262. (https://doi. org/10.1111/cen.13517)

Silber M, Miller I, Bar-Joseph H, Ben-Ami I \& Shalgi R 2019 Elucidating the role of pigment epithelium-derived factor (PEDF) in metabolic PCOS models. Journal of Endocrinology 244 297-308. (https://doi. org/10.1530/JOE-19-0297)

Tal R, Seifer DB, Grazi RV \& Malter HE 2014 Follicular fluid placental growth factor is increased in polycystic ovarian syndrome: correlation with ovarian stimulation. Reproductive Biology and Endocrinology 1282. (https://doi.org/10.1186/1477-7827-12-82)

Teede HJ, Misso ML, Costello MF, Dokras A, Laven J, Moran L, Piltonen T, Norman RJ \& International PCOS Network 2018 Recommendations from the international evidence-based guideline for the assessment and management of polycystic ovary syndrome. Human Reproduction 33 1602-1618. (https://doi.org/10.1093/humrep/ dey256)
Torchen LC, Idkowiak J, Fogel NR, O'Neil DM, Shackleton CHL, Arlt W \& Dunaif A 2016 Evidence for increased $5 \alpha$-reductase activity during early childhood in daughters of women with polycystic ovary syndrome. Journal of Clinical Endocrinology and Metabolism 101 2069-2075. (https://doi.org/10.1210/jc.2015-3926)

Wang JJ, Zhang SX, Mott R, Chen Y, Knapp RR, Cao W \& Ma JX 2008 Anti-inflammatory effects of pigment epithelium-derived factor in diabetic nephropathy. American Journal of Physiology: Renal Physiology 294 F1166-F1173. (https://doi.org/10.1152/ajprenal.00375.2007)

Xita N \& Tsatsoulis A 2006 Review: fetal programming of polycystic ovary syndrome by androgen excess: evidence from experimental, clinical, and genetic association studies. Journal of Clinical Endocrinology and Metabolism 91 1660-1666. (https://doi.org/10.1210/jc.2005-2757)

Yamagishi S-I, Inagaki Y, Nakamura K, Abe R, Shimizu T, Yoshimura A \& Imaizumi T 2004 Pigment epithelium-derived factor inhibits TNF-alpha-induced interleukin-6 expression in endothelial cells by suppressing NADPH oxidase-mediated reactive oxygen species generation. Journal of Molecular and Cellular Cardiology 37 497-506. (https://doi.org/10.1016/j.yjmcc.2004.04.007)

Yang S, Li Q, Zhong L, Song Y, Tian B, Cheng Q, Qing H, Xia W, Luo M \& Mei M 2011 Serum pigment epithelium-derived factor is elevated in women with polycystic ovary syndrome and correlates with insulin resistance. Journal of Clinical Endocrinology and Metabolism 96 831-836. (https://doi.org/10.1210/jc.2010-2140)

Yki-Järvinen H 2004 Thiazolidinediones. New England Journal of Medicine 351 1106-1118. (https://doi.org/10.1056/NEJMra041001)

Yoshida T, Yamagishi Si, Nakamura K, Matsui T, Imaizumi T, Inoue H, Ueno T \& Sata M 2006 Pigment epithelium-derived factor (PEDF) blocks the interleukin-6 signaling to C-reactive protein expression in Hep3B cells by suppressing Rac-1 activation. Life Sciences 79 1981-1987. (https://doi.org/10.1016/j.lfs.2006.06.034)

Zhang SX, Wang JJ, Gao G, Shao C, Mott R \& Ma JX 2006 Pigment epithelium-derived factor (PEDF) is an endogenous antiinflammatory factor. FASEB Journal 20 323-325. (https://doi.org/10.1096/fj.054313fje)

Zhang SX, Wang JJ, Dashti A, Wilson K, Zou MH, Szweda L, Ma JX \& Lyons TJ 2008 Pigment epithelium-derived factor mitigates inflammation and oxidative stress in retinal pericytes exposed to oxidized low-density lipoprotein. Journal of Molecular Endocrinology $\mathbf{4 1}$ 135-143. (https://doi.org/10.1677/JME-08-0011)

Received in final form 10 March 2020

Accepted 13 March 2020

Accepted Manuscript published online 13 March 2020 https://joe.bioscientifica.com https://doi.org/10.1530/JOE-19-0603
(C) 2020 Society for Endocrinology Published by Bioscientifica Ltd.
Printed in Great Britain 